\title{
COOPERATIVISMO AGRARIO EN LA COMUNIDAD VALENCIANA
}

\author{
Concepción Basanta Fernández \\ Doctora en Geografía \\ I.E.S. Mutxamel
}

\begin{abstract}
RESUMEN
El artículo contiene una síntesis del proceso de creación y difusión de la empresa cooperativa en la Comunidad Valenciana, así como del modelo de organización a escala local, regional, nacional y europeo. El cooperativismo agrario católico valenciano, bajo la dirección del P. Vicent, desarrollará al máximo sus posibilidades económicas marcando la diferencia con otras regiones de España. Los acontecimientos históricos repercuten en modificaciones legales que afectan a la estructura y funcionamiento de las cooperativas: desde la revolución liberal de 1868 hasta la integración en la Unión Europea. Mérito del cooperativismo agrario es haber conseguido la apertura de esta sociedad tradicional a nuevos métodos de trabajo y organización, lo que ha permitido a los campesinos ampliar sus derechos políticos y, especialmente, la mejora del nivel de vida como consecuencia de los aportes técnicos, comerciales y de gestión. En esta línea se valora la adhesión a la UE, destacando tanto las ayudas recibidas como las dificultades que puedan sobrevenir en razón de las negociaciones con los mercados exteriores y de la nueva PAC. Por último, el trabajo de campo hecho se concreta en breves reseñas de las cooperativas más destacadas comercialmente.
\end{abstract}

Palabras clave: cooperativismo agrario, sindicatos agrícolas católicos, Federaciones, Cajas Rurales, PAC.

\begin{abstract}
The article it's a synthesis of the creation and diffusion process of the cooperative venture at the Comunidad Valenciana, including the organization model on a global, regional, national and European scale.The catholic agricultural cooperativism, under the management of P. Vicent, will develop the maximum of its economical possibilities, setting with it the difference with other Spanish regions.The historical events have an impact on legal modifications that affects the cooperatives' structure and operation: from the liberal revolution on 1868 to the integration into de European Union.The agricultural cooperativism's merit it's been reach the opening of this traditional society to new working and organization methods, which let the farmers widen them politics rights and, specially, to improve them life style as a consequence of the technician, commercial and administration contributions. In this level it's valuable the adhesion to the UE, emphasizing any help
\end{abstract}


received as the difficulties that could strike because of the negotiations with the external markets and the new PAC. Finally, the fieldwork made is concreted on a short review of the most relevant commercially cooperatives.

Palabras clave: agrariam cooperativism, Catholic agricultural syndicates, Federations, Rural Banks, CAP.

\section{Introducción}

La Asamblea General de las Naciones Unidas, en su 66 reunión plenaria, el pasado 31 de octubre, de acuerdo con la resolución 64/136 de dicho organismo, promovió la celebración del 2012 como el Año Internacional de las cooperativas, con el fin de potenciar el conocimiento, el debate y la promoción de este modelo empresarial bajo el lema: Las cooperativas ayudan a construir un mundo mejor. Se pretende provocar el interés público por las cooperativas, difundir los beneficios que reportan a sus miembros y la contribución que hacen al desarrollo. En último término se busca apoyar la creación de cooperativas como modelo de desarrollo social y económico. Estas empresas promueven un empleo estable, el arraigo en el territorio y pueden ser una tabla de salvación para los trabajadores que ven reducirse las posibilidades laborales con la destrucción del tejido industrial.

Con motivo de dicho evento, surge la publicación de este trabajo de investigación. Los objetivos de partida fueron, entre otros, conocer la red de cooperativas agrarias en nuesto entorno más próximo. Trazar la ruta seguida por el movimiento cooperativo desde el corazón de Europa y su diversificación regional al llegar a la Península Ibérica. Documentar las peculiares características de su evolución económica, legal y política en el territorio nacional y en la Comunidad Valenciana. La superposición de estos aspectos evidencia la diversidad de actividades del movimiento cooperativo, la fuerza creadora en el medio rural y la pérdida de vitalidad en las ciudades. No obstante este desarrollo se da sólo en las zonas de predominio de la pequeña y mediana propiedad del norte y levante español. En su devenir intervienen personajes del clero, la nobleza o la clase media agraria, cuyas biografías marcan hitos en la lucha por la pervivencia del asociacionismo obrero y cooperativo, manteniéndolo al margen de las ideologías revolucionarias de la época. En la difusión de los principios cooperativos y en la elaboración de los estatutos de estas empresas dejan su impronta que se refleja en la organización del asociacionismo rural regional. Para la consecución de los objetivos previstos se han analizado y consultado diversas fuentes documentales, tanto directas como indirectas. Entre las primeras cabe destacar la información facilitada por las empresas (Convocatorias de Asambleas, folletos informativos para la difusión entre sus miembros, informes de gestión), fuentes estadísticas facilitadas por organismos públicos y por las propias cooperativas. La realización de entrevistas con directivos, técnicos y políticos permitió abrir nuevas vías de investigación, ampliar fuentes documentales, observar aspectos técnicos y humanos relacionados con los procesos de producción y distribución. La otra línea de trabajo fue la búsqueda de documentos en hemerotecas, bibliotecas y archivos municipales. Las propias cooperativas suelen disponer de archivos en los que se guardan publicaciones locales (programas de fiestas) o propias sobre la historia de la entidad o algún aspecto de la actividad cooperativizada. Hay, además, numerosas publicaciones de los que se conocen como propagandistas de los principios cooperativos sobre los efectos benefactores y sus reflexiones acerca del futuro de este modelo de producción. En la bibliografía adjunta están reflejados los autores históricos del siglo XIX como Polo Bernabé, Ramos Bascuñana, P. Vicent, Lassala, y de principios del siglo XX: Rivas Moreno, Carrión. A partir de los setenta, las publicaciones sobre el tema se hacen colectivas promovidas desde instituciones 
públicas (Instituto de Cooperación, Ministerios de Agricultura, de Trabajo) y universidades como la de Zaragoza, Madrid o Santiago. Con estas publicaciones se pretente no sólo dar a conocer la teoría y la práctica cooperativa en España y el mundo, sino solidarizarse políticamente con el tema, visto siempre con recelo desde el poder.

\section{Los orígenes del movimiento cooperativo europeo}

En Inglaterra y, más tarde, en el resto de países europeos, al lado del movimiento sindical se desarrolla el movimiento cooperativo, que presta una sólida ayuda en los períodos difíciles. Los años treinta, del siglo XIX, coinciden con la crisis del sector textil, a lo que hay que añadir el fuerte crecimiento de la población, las transformaciones en la estructura de propiedad (los cercamientos), y la depreciación del valor de la mano de obra frente a la máquina ${ }^{1}$. En la década de los cuarenta, puede descubrirse una toma de conciencia hacia los problemas sociales de las clases dirigentes de Inglaterra, Alemania, etc., que despertará el interés por las nuevas formas de organización de la clase obrera y, más concretamente, por las asociaciones de consumo. Así, Schulze, inspirándose en el movimiento cooperativo francés y en la experiencia de los bancos escoceses, fundó, en 1850, la primera sociedad de crédito y, a partir de ahí, una organización nacional de cooperativas federadas por regiones, en Alemania (Bancos Populares) ${ }^{2}$. Este personaje está considerado como el máximo teórico del cooperativismo liberal alemán. Otra experiencia que tuvo gran resonancia en el ámbito europeo, y muy pronto en la Comunidad Valenciana de la mano del Padre Vicent, fue la llevada a cabo por el economista y burgomaestre alemán Friedrich Wilhelm Raiffeisen. En 1874 creó la banca alemana Raiffeisen, bajo la fórmula de sociedad anónima. Para Mateo y Palacio $^{3}$, estas cooperativas de crédito agrícola no son rochdalianas pues vulneran un par de principios o, al menos uno, el de la democracia, debido a que los cargos de responsabilidad se aceptaban desinteresadamente, sin recibir retribución en razón del cargo. Ello supuso, de hecho, que la toma de decisiones correspondiera a los impositores que eran los que, en última instancia, comprometían su fortuna. Sin embargo, la mayor parte de los investigadores o analistas de la cooperación coinciden en señalar a la cooperativa de Rochdale como el punto de arranque del moderno cooperativismo, a pesar de la fuerte controversia habida entre ingleses, alemanes y franceses por la atribución de los antecedentes históricos del movimiento ${ }^{4}$.

Los Pioneros Equitativos de Rochdale, en su mayor parte tejedores, organizaron una sociedad cooperativa de consumo, en 1844 , que se extendió por gran parte del Reino Unido y fue el inicio de un gran movimiento ${ }^{5}$. Formularon los Principios Cooperativos o pautas mediante las cuales los cooperativistas ponen en práctica sus valores, en los que se inspirará, en el futuro, todo el Cooperativismo ${ }^{6}$. Estos Principios apenas han experimentado cambios desde entonces. El XXIII Congreso de la Alianza Cooperativa Internacional (A.C.I.), celebrado en Viena, en 1966, revisó su redacción y secuenciación, añadiendo un sexto principio. El nuevo ordenamiento quedó así:

$1^{\circ}$ - Libre adhesión y baja voluntaria.

$2^{\circ}$ - Control democrático e igualdad de derechos.

\footnotetext{
1 NIVEAU (1979: 110-146); DOBB (1973: 5).

2 RIVAS MORENO (1919: 6-8); BASANTA FERNÁNDEZ (2002: 10).

3 MATEO Y PALACIO (1972: 94).

4 LLOBREGAT HURTADO (1990: 4); NIVEAU (op. cit. p. 120); ALONSO (1974: 53-68).

5 HERKNER (1916); LLUIS I NAVAS (1972: 212).

6 REVENTÓS (1960: 57-58); PÉREZ TURRANO (1966: 25); CIURANA et al. (1963: 31 a 36); LLOBREGAT HURTADO (1990: 4) y ALONSO (1974: 53-68).
} 
$3^{\circ}$ - Limitación de interés al capital.

$4^{\mathrm{o}}$ - Proporcionalidad en la distribución de beneficios.

$5^{\circ}$ - Educación y promoción cooperativa.

$6^{\mathrm{O}}$ - Cooperación entre cooperativas.

Treinta años más tarde, el Congreso del Centenario de la A.C.I., celebrado en Manchester, en septiembre de 1995, adoptó la Declararción de Identidad Cooperativa, auspiciada por el profesor canadiense Ian MacPherson. En ella se define a la cooperativa como asociación autónoma de personas voluntariamente unidas para resolver sus necesidades y aspiraciones económicas, sociales y culturales, mediante una empresa democráticamente controlada y que pertenece a todos. ${ }^{7}$ Paralelamente se afronta la reescritura de los Principios, que aumentan a siete, dejando abierta la puerta a importantes cambios económicos, al suprimir la limitación de interés al capital. La nueva redacción es la siguiente:

$1^{\circ}$ - Afilicación voluntaria y abierta.

$2^{\circ}$ - Control democrático por parte de los miembros.

$3^{\circ}$ - Participación económica de los miembros.

$4^{\circ}$ - Autonomía e independencia.

$5^{\circ}$ - Educación, formación e información.

$6^{\circ}$ - Cooperación entre cooperativas.

$7^{\circ}$ - Interés por la comunidad.

\section{Difusión del sistema cooperativo en el ámbito valenciano}

Desde centroeuropa - Francia tendrá un papel especial-, llegarán a la Península las nuevas fórmulas cooperativas, a través de las regiones más desarrolladas, más norteñas, y a nuestra Comunidad. Las primeras experiencias son fruto de los contactos de la izquierda francesa con los políticos emigrados a dicho país (en especial el cartagenero Fernando Garrido y los grupos furieristas ligados al periódico La Atracción), en un momento en que republicanismo, socialismo y cooperativismo aún no habían iniciado sendas muy diferenciadas $^{8}$. El Primer Congreso Obrero Español, celebrado en Barcelona, en 1870, marca el inicio de la escisión del Cooperativismo del movimiento obrero, tras el rechazo manifestado por la ponencia de Cooperación. No obstante, y según Reventós, la Comisión de este Congreso atribuirá un papel revolucionario a la cooperación entre agricultores. Lo cierto es que a partir de este momento el ideal cooperativo será abandonado por la izquierda y recogido, entonces, por los grupos conservadores. Se publican con mayor frecuencia obras divulgadoras de la filosofía cooperativa de la mano de hombres ajenos al movimiento obrero. También, se ponen en marcha las primeras cooperativas de crédito9 .

La trascendencia de la cooperativa de Rochdale, debido a los buenos resultados económicos que estaba obteniendo y la grave crisis del sistema político, a mediados del siglo XIX, actuarán en favor del reconocimiento y apoyo legal a este tipo de asociaciones. La Constitución española de 1869 proclamó el libre ejercicio del derecho de asociación. Ese mismo año una ley, de 19 de octubre, sobre libertad de creación de Bancos y Compañías mercantiles, disponía que las cooperativas podrán adoptar la forma que los asociados crean conveniente establecer en la escritura fundacional. Y, el Código de Comercio de 1885, artículo 124, regulará el fenómeno cooperativo, aunque sólo contemple tres tipos

7 GINER (1996: 16-18).

8 LLUIS (op. cit. p. 213); FONTANA (1975: 94).

9 POLO DE BERNABÉ (1867); RAMOS BASCUÑANA (1880); PÉREZ PUJOL (1872); VICENT (1893 y 1905); RIVAS (1904). 
de asociaciones: las de producción, las de crédito y las de consumo. Todas las que quedan al margen del Código encontrarán en la Ley de Asociaciones de 1887 confirmación legal, reforzada, posteriormente, por el Código Civil, de 24 de julio de 1889.

Las cooperativas de consumo instaladas en los centros urbanos de la Comunidad, con un amplio hinterland agrario, representan el arranque de la moderna Cooperación en el campo. En esta primera fase, último tercio del siglo XIX, se distinguen tres regiones funcionales en donde se organizan redes de cooperativas de consumo o de crédito autónomas que, con el tiempo, devienen en agrarias. Ya en el siglo XX, se crean Federaciones de cooperativas por afinidad ideológica. Una de ellas se extiende desde Cataluña hasta Valencia, a través de la Unión Agraria Española, ligada a organizaciones institucionales como las Cámaras Agrícolas y la Real Sociedad de Amigos del País. La otra, de la mano del P. Vicent y la organización católica seglar de los jesuitas (los propagandistas), partiendo de la ciudad de Valencia alcanza a toda la Comunidad y a la provincia de Tarragona, penetrando por Aragón hacia el noroeste. La tercera región se extiende por las áreas castellanas del interior de Alicante, Valencia y Murcia, conectadas con la capital del Estado, a través de las organizaciones obreras de carácter anarquista o socialista ${ }^{10}$. Los nombres de algunas de estas primeras cooperativas, de las que no se sabe a ciencia cierta su función esencial, sugieren un origen agrario y sindical, entre las que se encuentra El Campesino, fundada en 1856, considerada como la cooperativa de consumo más antigua de Valencia. Según el almanaque de Las Provincias de 1884, existían en Valencia, por esas fechas, otras cooperativas denominadas La Agrícola y El Amparo de la Agricultura; también se crearon, en Russafa, según la misma fuente, La Favorecedora de la Agricultura y La Agrícola Protectora; La Agrícola de Cullera; La Protectora de la Agricultura de Pinedo, y La Protectora de Tavernes de Valldigna. En la Safor se fundaron varias, a finales de siglo: en Simat, Bellreguard, Benifairó, llegando el movimiento hasta la La Font de la Figuera, en 1899. Paralelamente, se ponen en marcha las primeras cooperativas de crédito: en 1881 comenzó a funcionar la Caja de Socorros y Ahorros de Orihuela, conocida como La Agrícola para facilitar a los labradores e industriales metálico, granos, abonos, semillas, máquinas, animales y viviendas en condiciones determinadas. En 1890, Pérez Pujol contribuye personalmente a la creación de la Cooperativa de Crédito de Vara de Quart; en 1902, se funda la Caja Rural del campo de Elche y la Hacienda de Río Florido-Almoradí; en 1903, la Cooperativa de Crédito Popular de Quart de Poblet; en 1904 empieza a funcionar la Caja de Ahorros de Nuestra Señora de Monserrate en Orihuela; de 1905 es el Banco Bolbaitiano y un largo etcétera ${ }^{11}$. Estas instituciones, al contrario que las de consumo, tienden a organizarse en las comarcas con agricultura de secano, ya que las Cajas Rurales son una solución para los pequeños propietarios y arrendatarios.

Con fecha 14 de noviembre de 1890 se establecen las Cámaras Agrícolas, que van a jugar un papel destacado en la promoción del asociacionismo (gremios y cooperativas) entre propietarios agrícolas, especialmente en Cataluña, desde donde se promocionará la idea de la Federación de propietarios rurales de España; esta Federación fue constituida, a finales de marzo de 1903, con el nombre de Unión Agraria Española; en ella se integró la Federación Agraria de Levante que, a través de la Real Sociedad de Amigos del País de Valencia, promocionará el cooperativismo en el sector citrícola en esta provincia y en Castellón, de la mano de Lassala Emo y Carlos Sarthou ${ }^{12}$.

\footnotetext{
10 ÁLVAREZ RUBIO (1977: 22); VALDÉS (1975: 29-31).

11 GARRIDO (1986: 111); RIVAS (1904).

12 LASSALA (1909).
} 


\section{Agremiación y cooperación católica}

La acción social católica ${ }^{13}$, desarrollada por el jesuita P. Vicent desde el colegio San José de Valencia, se aplicará, en una primera etapa, a la creación de los Círculos de Obreros Católicos, institución que ya había sido introducida desde Europa en la Comunidad Valenciana por el Padre Pastells y que, a finales de siglo, se renueva. En 1893, el P. Vicent publica Socialismo y Anarquismo, obra en la que incluye un Reglamento-tipo para los Círculos de Obreros Católicos. Entre los objetivos de esta institución, el económico ocupa un lugar destacado. Los medios para conseguirlo consisten en la creación de una Caja de Socorros Mutuos, el fomento de toda clase de asociaciones para la compra de semillas, herramientas, abono, etc., y para la indemnización mutua por las pérdidas sufridas en las industrias agrícolas; para la adquisición de primeras materias, instrumentos y máquinas así como la fundación de una Caja de Ahorros y Monte de Piedad, y, finalmente ${ }^{14}$, dicha obra incluye, en el anexo, un modelo de Estatutos para facilitar la fundación de cooperativas de consumo y un Reglamento modelo de gremio de labradores en donde se concretan, por primera vez, los objetivos de la cooperación agrícola en España (en la sección primera dedicada al Consejo Directivo). Entre sus objetivos se halla, proporcionar medios eficaces para la obtención de buenos rendimientos (semillas, plantones...), concediendo especial importancia a la difusión de las innovaciones técnicas y la transmisión de información sobre precios de mercado a los productores.

Tras el fracaso de muchos de los Círculos, el P. Vicent propondrá la sustitución de éstos por los Gremios en la Asamblea de Corporaciones Católicas Obreras, celebrada en Castellón, en 1896. Y, en el Congreso Católico de Burgos de 1899, orientará la acción social católica hacia el medio rural, en donde aún se conservan fieles a la Religión, al revés de lo que ocurre con los obreros de los centros fabriles. Aunque, lo verdaderamente innovador será la autorización para que las obras económicas (sindicatos agrícolas, sociedades de socorros, cooperativas...) puedan constituirse fuera del Círculo Católico de la población. Para el gobierno del Sindicato establece un poder dual: eclesiástico y seglar, y de él dependerán las instituciones económicas. El único compromiso formal entre los socios protectores (aportaban dinero) y numerarios será la ayuda mutua. Es conveniente aclarar que, en la terminología utilizada por el P. Vicent y el movimiento católico, se suele denominar Sindicato a aquellas obras que tienen por objeto la venta de las cosechas y los gremios de labradores, mientras que, cooperativa se refiere a la constituída para la compra de primeras materias, o sea de consumo ${ }^{15}$.

Del 10 al 13 de mayo de 1905 se celebró en Valencia la primera Asamblea Regional de Corporaciones Católicas, a la que acudieron representantes de las provincias eclesiásticas de Valencia, Zaragoza y Tarragona; de ella salió la Federación de Cooperativas de Producción, Crédito y Consumo en la que se integraron 31 entidades, algunas de fuera de la Comunidad. Esta Federación estableció una oficina para la venta de las cosechas y para actuar de cara a la exportación. Un año más tarde, según el P. Vicent, agrupaba a más de 100 Sindicatos y, en casi todos los Círculos y Gremios, se había establecido una cooperativa para la compra y venta de semillas, abonos y otras sustancias o aparatos de uso frecuente para los agricultores; también en algunas, se vendían comestibles. A partir de 1906, defenderá la autonomía económica de la organización sindical, para no estar a expensas de los socios protectores. A este fin recomendará que en cada pueblo se constituya una Caja de Ahorros cooperativa. Al tiempo, irán apareciendo distintas disposiciones legales, bajo su influencia

13 LLORENS (1954); GARCÍA NELA (1996: 138-140).

14 VICENT (1893: 251).

15 VICENT (1905: 53-55). 
o la de sus más directos colaboradores para regular el movimiento asociativo ${ }^{16}$. Los pilares sobre los que se desarrollará el cooperativismo agrario los fija la Ley de Sindicatos Agrícolas de 28 de enero de 1906, como resultado del volumen e importancia adquirida por el movimiento católico. De Iranzo ve detrás de esta normativa la mano del P. Vicent y sus discípulos, en especial a Victoriano Flamarique ${ }^{17}$. Esta ley concedió sustanciales ventajas fiscales a la actividad agraria y, bajo su amparo, se fundarán Sindicatos por todos los rincones de la geografía nacional. Las sociedades agrarias preexistentes se convierten en sindicatos o desaparecen. Un año más tarde, la Ley de Colonización y Repoblación Interior de 30 de agosto de 1907, y su Reglamento de 23 de octubre de 1918, llegan a establecer cooperativas obligatorias. El Reglamento de dicha ley preveía hasta quince finalidades para las Asociaciones cooperativas de colonos. Por ello, este texto constituye, para Reventós, la primera auténtica regulación de nuestras cooperativas y, para Borjabad, el antecedente histórico de las futuras cooperaciones agrícolas ${ }^{18}$.

La expansión de las entidades católicas, paradójicamente, se verá frenada en etapas de calma social, y los momentos de máxima vitalidad corresponderán con las etapas de reactivación del movimiento obrero. Así, la dura crisis que sobreviene a la Gran Guerra contribuirá al despliegue y expansión del cooperativismo agrario por toda nuestra geografía. No obstante, muchos de estos sindicatos y cooperativas, faltos de canales de crédito adaptados a sus necesidades fracasaban, hasta que, en 1917, se creó la Caja Central de Crédito Agrícola para operar a favor de las Asociaciones y de los agricultores. Gracias a esta iniciativa, en 1919 se pudieron construir las primeras bodegas cooperativas valencianas en Cheste y Pedralva; al año siguiente, la de Turís y otras muchas. Ya en 1925 se creará el Servicio Nacional de Crédito Agrícola.

En el primer tercio del siglo XX, frente a la corriente agrarista española que propugnaba como base de la reforma agraria la revisión del régimen de propiedad de la tierra, los católicos oponen la revisión y mejora de su cultivo, defendido por el italiano Solari y sus discípulos. A este fin, se establece como objetivo preferente el avance técnico, y la Federación de sindicatos católicos valencianos tenderá a mantener el número de pequeños propietarios mediante la constitución de estas entidades en cada pueblo, siendo una excepción en el panorama político español. Otras actuaciones en este sentido, llevadas a cabo por las Federaciones fueron:

- La defensa de los intereses económicos de los asociados, en especial lo relativo a necesidades de transporte y mercados.

- La construcción de infraestructuras de regadío para incrementar la rentabilidad de la producción agraria.

- Favorecer la adquisición de máquinas, herramientas y útiles de trabajo necesarios, bien de forma colectiva, bien de forma privada, mediante el pago aplazado.

- Organizar cooperativas de crédito, que garantizarán el acceso a préstamos, con bajo interés, para la adquisición de la propiedad, la ampliación de ésta, o la renovación de las técnicas de cultivo.

- Realización de campañas a fin de divulgar las nuevas técnicas de cultivo y la aplicación de abonos para mejorar el aprovechamiento y rentabilidad de las tierras.

16 VICENS VIVES (1974: 154-155); Vicens, cree posible que, bajo su influencia, se creara la Comisión de Reformas Sociales, en diciembre de 1883, que se transformará, en 1905, en Instituto de Reformas Sociales.

17 Sacerdote navarro, «el cura de Olite», fundador de la primera Caja Rural tipo Raiffeisen y promotor de otras organizaciones cooperativas agrarias en la región, a principios del siglo XX. Vid, MAJUELO GIL, E. y PASCUAL BONIS (1991: 38).

18 BORJABAD I GONZAL (1984). 
- La importación de materias necesarias para la fabricación de abonos y su posterior venta a los socios con un ahorro del 15/20 por ciento en relación al mercado libre; también podían adquirirlos al fiat o a crédito.

- La construcción de caminos rurales, locales sociales, bodegas, almazaras o naves comerciales cofinanciadas por los socios de la cooperativa o de la sección correspondiente.

- Proporcionar trabajo los días de paro a los socios obreros o pequeños propietarios cuya parcela no alcanza los rendimientos necesarios para el mantenimiento de la economía familiar.

\section{Federación nacional de la cooperación}

En el marco del movimiento católico de la Comunidad Valenciana, la idea de crear una Federación, ya planteada por el P. Vicent un año antes de su muerte, se hará realidad el 5 de abril de 1916. El acuerdo se tomó en una asamblea a la que acudieron 47 sindicatos. A partir de este momento se inicia un ritmo de adhesiones acelerado hasta alcanzar los 214, en 1917. Cuando, a fines de ese año, se constituye la Confederación Nacional Católica Agraria con 18 federaciones, la Valenciana es la más numerosa en cuanto a socios y la más extensa geográficamente, incluyendo 167 Sindicatos en Valencia, 29 en Alicante, 16 en Castellón, además de 1 en Granada y otro en Teruel. En el aspecto económico, sorprende a Josefina Cuesta ${ }^{19}$ el hecho de que figurara en cuarto lugar por el movimiento general de fondos y que ostentara la mayor cuantía en el movimiento relativo a los sindicatos (105.558 pesetas), cuando el promedio global estaba en 38.849 pesetas. Además, con abundantes imposiciones, no llegaban a consumir un tercio de éllas. Mayayo coincide en señalar la diferencia de fondos acumulados por los sindicatos de Tarragona ${ }^{20}$ que, en 1923, duplicaban la media de capital por socio, con 155.558 pesetas, respecto al resto de sindicatos de la Federación Catalano-Balear. Esto nos hace pensar en una concepción diferente de la organización cooperativa valenciana, auspiciada por el P. Vicent, menos caritativa y más empresarial.

Aún así, la Federación Valenciana quedará muy tocada tras la actuación contrarevolucionaria desplegada por ciertos sectores de la misma que, en la crisis de 1919, provocarán su militarización y ruina. A ello se sumará el hundimiento de los precios agrarios y la pérdida de beneficios de las cooperativas. En consecuencia, muchos sindicatos la irán abandonando y creando nuevas federaciones. En febrero de 1919 se constituyó la Federación de Sindicatos Agrícolas Católicos de Orihuela, a instancias de Antonio Monedero, integrada por el sindicato de esta localidad y los de Rafal, Redován, Molins, Formentera del Segura, San Bartolomé, Desamparados, La Murada, La Matanza y Benferri. En 1920, 34 sindicatos de los montes de Benicadell y Mariola constituyen un Sindicato comarcal ${ }^{21}$. Tres años más tarde, las entidades federadas de la provincia de Castellón constituirán su propia federación.

19 CUESTA (1978: 208-209).

20 El P. Vicent, tras graduarse en Ciencias en la Universidad de Sevilla, fue trasladado a Manresa como profesor, fundando allí su primer Círculo de Obreros Católicos (1865). La revolución de 1868, que implicó el destierro de las Órdenes Religiosas, le llevó a viajar por Francia, Alemania y Bélgica donde las asociaciones de obreros católicos tenían verdadera importancia. A su regreso puso en marcha nuevos Círculos en la diócesis de Tortosa, al tiempo que inició su campaña en la de Valencia, en donde fija su residencia. MAYAYO I ARTAL (1995: 123). Comparando los datos de 1908 del Consejo Nacional de Corporaciones Obreras Católicas y los facilitados sobre cooperativas católicas por el P. Vicent, se deduce que sólo las cooperativas valencianas pusieron en marcha cooperativas de consumo al servicio de los gremios.

21 ABADÍA (1994: 31). 
Es justo atribuir al cooperativismo católico el mérito de haber logrado triunfar en zonas tan poco aptas a cualquier novedad, y tan cerradas a los esquemas individualistas, como los ambientes campesinos ${ }^{22}$. A ello contribuyó la organización de base familiar en decurias y centurias, facilitando una comunicación más directa y personalizada entre los miembros del sindicato; ahora bien, este triunfo se registra sólo en regiones de predominio de la pequeña y mediana propiedad. Y a pesar de su carácter jerárquico, el cooperativismo católico ha sido una de las vías que ha permitido a los campesinos ampliar sus derechos políticos ya que periódicamente celebraban Asambleas generales en donde los socios hacían uso de su voto, tras los debates. Por ello, señala Garrido, el movimiento cooperativo ha actuado com a eix de vertebració i d'articulació social en el mundo rural, combatiendo. asimismo, el analfabetismo. Todo ello, unido a las actividades económicas esenciales, contribuyó a romper el aislamiento ancestral del hombre del campo.

Del movimiento no sólo participarán los católicos, también intervienen otros grupos políticos, en especial el partido socialista. La normativa vigente prohibía la fundación de más de un sindicato en cada localidad por lo que, socialistas, católicos y anarquistas se van a disputar el apoyo y fomento de las cooperativas. Rivas Moreno nos dice que la U.G.T., en la Asamblea de septiembre de 1918, había recomendado a sus socios para las empresas agrícolas cuidar de acomodar sus actos a las normas cooperativas ${ }^{23}$. El período de mayores adhesiones al socialismo se dió entre 1920 y 1921. Por entonces, dentro del sindicato socialista se hallaban: la Federación Regional Levantina de Agricultores a la que pertenecían, sobre todo, sociedades agrarias radicadas en la provincia de Valencia. Las entidades agrícolas de Alicante, Murcia y Albacete se agrupaban en la Federación Comarcal Agraria de Levante. Una tercera organización era la Federación Provincial de Castellón ${ }^{24}$.

Con el tiempo se irán estableciendo lugares comunes al movimiento cooperativo sin más.

El Primer Congreso Nacional de Cooperativas, celebrado en el paraninfo de la Universidad de Barcelona, en 1913, por iniciativa de la Cámara Regional de Cataluña y Baleares, marca el inicio de la política de acercamiento. En la Presidencia de este Congreso, al que acudieron 123 delegados en representación de 255 cooperativas y sindicatos, estaba Martínez Velasco, líder de la Confederación Católica Agraria y, en el acto de clausura, tomó parte el Padre Palau de Acción Social Popular ${ }^{25}$. No obstante, las agrias discusiones entre socialistas y católicos impedirán la creación de una Federación Nacional de Cooperativas hasta 1928, tras la elaboración del Anteproyecto de Ley de Cooperativas de 1927, por una comisión mixta coordinada por Gascón y Miramón ${ }^{26}$. La Asamblea constituyente de dicha Federación acordó establecer, en el artículo $2^{\circ}$ de sus Estatutos, que este órgano no se ocuparía de política ni de religión al considerar la cooperación como un terreno neutral en el que personas de distintas opiniones y de las más diversas creencias pueden unirse y trabajar en común.

Dada la importancia de las organizaciones cooperativas, por Real Orden de 14 de enero de 1925, se encomienda al Instituto de Reformas Sociales la creación de una Comisión para, conforme a unas Bases, preparar una Ley de Cooperativas. Gascón y Miramón, Jefe de Cooperación del Instituto, se encargará de dar forma al texto y presentarlo ante el Pleno de la Comisión, en 1927, para su aprobación. Pero, este Anteproyecto de Ley de Cooperativas, fruto del esfuerzo de un grupo de entusiastas cooperativistas de las más diversas

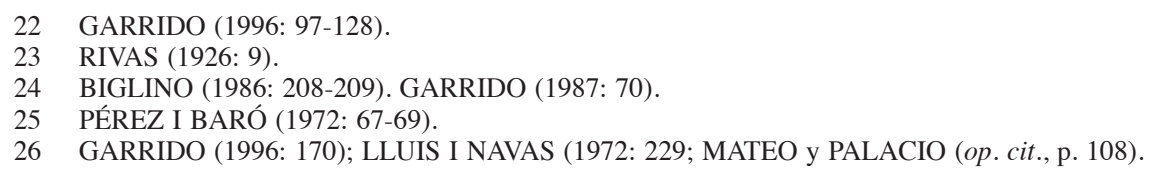


creencias, quedó archivado hasta que, proclamada la II República, será promulgado como Ley por Largo Caballero, a la sazón, ministro de trabajo ${ }^{27}$.

La crisis de 1929 acarrea la pérdida de influencia de los católicos en el mundo agrario frente a socialistas y anarquistas.

Con la proclamación de la Segunda República, superados los primeros escollos y dificultades de comunicación con la nueva Administración, las Federaciones de Sindicatos Agrícolas de Castellón, Valencia y Orihuela, alcanzaron cotas de crecimiento importantes. La primera norma especial de Cooperación fue promulgada por Decreto de 4 de julio de 1931, y ratificada por Ley de 9 de septiembre del mismo año; esta ley clasificaba a las cooperativas agrícolas como asociaciones de profesionales, grupo al que dejaba exento de ayudas y beneficios. Por esta razón, y porque dicha norma había sido presentada como una conquista socialista, no contribuyó a mejorar las relaciones entre las organizaciones cooperativas. Así, la cooperación rochdaliana se extenderá en el medio urbano mientras que los Sindicatos agrícolas continuarán alejados de la Administración y bajo la tutela de la Iglesia Católica.

En 1932, al celebrarse en Bilbao el IV Congreso Nacional de Cooperativas, se fijan en 18 las cooperativas agrícolas adheridas a esta organización, de un total de 465 entidades $^{28}$. Al estallar la Guerra Civil, con el derrumbamiento del poder establecido durante la República, se impondrán las colectivizaciones, firmemente defendidas por anarquistas y ugetistas frente al partido comunista, los partidos republicanos burgueses y ciertos sectores del Partido Socialista $^{29}$. La presencia al frente del Ministerio de Agricultura del comunista Vicente Uribe hizo cambiar el rumbo del gobierno republicano hacia una política anticolectivista y favorecedora de la implantación de cooperativas en los pueblos. Reconocían tres tipos de cooperativas: de campesinos o cultivadores independientes en régimen individual, las constituídas en comunidades de agricultores que cultivaran parcelas individuales procedentes de tierras incautadas y las formadas por dos o más asociaciones colectivistas. Quedaban excluídas, según Abad, las comunidades que adoptasen el sistema de explotación colectiva de la tierra, con lo que se les cerraba el paso a las ayudas. Esta legislación obligó a las colectividades anarquistas a redactar un Estatuto de Colectividades-Cooperativas Confederadas de Trabajadores Campesinos, para su legalización. Es por ello que para Pérez Turrano la colectivización se limitó a transformar las empresas privadas en empresas cooperativas. No obstante, Minz demuestra cómo los autogestionarios se refieren indistintamente a colectividad y cooperativa, confundiendo el significado de ambos términos. Resumiendo, entre cooperativas y colectividades, Gil Olcina afirma que el fenómeno revolucionario afectó a más de tres millones de hectáreas, siendo de una magnitud considerable en algunos sectores, como la citricultura, que quedaron bajo control sindical al ponerse de acuerdo las dos centrales mayoritarias ${ }^{30}$.

\section{La unificación forzada de la posguerra}

Antes de terminar la guerra, Franco decretó la confiscación de todos los bienes y efectos pertenecientes a determinadas Organizaciones Sindicales relacionadas en las Órdenes de 10 de enero de 1937 y 6 de febrero del mismo año, los cuales pasarán a ser propiedad de Falange y cuya Delegación Nacional las incorporará a la Delegación Nacional de Sin-

27 LLUIS I NAVAS (1972: 236-237); BORJABAD I GONZALO (1984: 96); PÉREZ I BARÓ (1972:

71-72); REVENTÓS (1960: 203).

28 CARRIÓN (1973: 357-367)

29 ABAD (1991: 58); PAVÍA (1992: 16)

30 PÉREZ TURRANO (1996: 78); MINZ (1986: 57-67); GIL OLCINA (1989: 57-58). 
dicatos. Según un informe de la Generalitat de Cataluña de 1984, hubo una veintena de sindicatos agrícolas cuyo patrimonio fue confiscado en la Comunidad Valenciana. El 27 de octubre de 1938, en la denominada zona nacional, se dicta la Ley de Burgos, con carácter transitorio, modificando el régimen de las Sociedades Cooperativas. Con esta Ley se inició una nueva etapa «presidida por el deseo de sustituir la concepción liberal y democrática de la sociedad cooperativa, por otra autoritaria y jerarquizada, en la que lo sindical y lo cooperativo quedasen confundidos $\gg^{31}$.

La Ley de Unidad Sindical, de 26 de enero de 1940, que derogaba la Ley de Cooperación de 1938, prohibirá cualquier tipo de organización o acción sindical al margen de la estatal. Poco después, la Ley de Colonización de Interés Local de 25 de noviembre de 1940, que representa el punto de arranque del nuevo proceso asociativo promovido por el Régimen, dio origen al nacimiento de los Grupos Sindicales de Colonización. Mediante la Orden de 11 de junio de 1941, el gobierno militar determinó, a su vez, que las agrupaciones debían adoptar la denominación de Grupos Sindicales si querían percibir las ayudas contempladas por la Ley. Éstas podían ser empleadas para una obra o mejora de interés colectivo, para constituir grupos de cultivo o explotaciones en común.

La Ley de 2 de septiembre de 1941 derogó la de Sindicatos Agrícolas de 1906 e integró en la Organización Sindical a todos los Sindicatos, sus Federaciones y Confederaciones, respetando la personalidad jurídica y autonomía patrimonial de las cooperativas. Sin embargo, al finalizar la guerra se había organizado el bloqueo de cuentas, correspondientes a una ralación de entidades, a partir de una Orden del Ministerio de Hacienda. Fue así como muchas colectividades o cooperativas agrícolas valencianas se encontraron dentro del grupo de cuentas declaradas improtegibles y las que mayores dificultades encontraron para ser desbloqueadas ${ }^{32}$.

La Ley de 2 de enero de 1942 abre otro período del cooperativismo agrario valenciano (primera norma legal que concede entidad propia a las Cooperativas del Campo). Esta norma incorpora definitivamente las cooperativas a la Organización Sindical del Movimiento, mediante la Obra Sindical de Cooperación dependiente, a su vez, del Ministerio de Trabajo. Dicha Ley supuso un cambio considerable, respecto de la de 1931, en materia de relaciones con el Estado, aunque el régimen interno de las cooperativas se apartaba poco de aquella normativa ${ }^{33}$. Las funciones de la Confederación Católica Agraria fueron absorbidas por la Unión Nacional de Cooperativas del Campo (UNACO), constituida el 1 de mayo de 1942, que agrupaba, a su vez, a las Uniones Territoriales de Cooperativas (UTECOS) de la rama correspondiente. Pero, para Abadía, lo que determinó la liquidación definitiva de la CNCA y, con ella, la organización independiente del cooperativismo agrario, fue la publicación de la Ley de Unidad Sindical Agraria, en el B.O.E. del 8 de agosto de 1944, y su Reglamento, de $1945^{34}$.

La etapa de adaptación a la nueva normativa tuvo lugar en momentos de grave crisis económica. El cooperativismo valenciano era prácticamente inexistente, según Abad. El estallido de la Segunda Guerra Muncial frenó la importación de productos nitrogenados para la producción de abonos. La paralización de las cooperativas llegaría a su punto máximo en 1954, año de la normalización del mercado de fertilizantes. En este contexto ruinoso se da la Orden de 9 de septiembre de 1947 por la que se fija un estatuto fiscal a las cooperativas y, por Decreto de 27 de abril de 1951, se separó, a efectos fiscales, el patrimonio de la Delegación Nacional de Sindicatos, del privado e independiente de otros

\footnotetext{
31 VALDÉS (1975). BASANTA (2012: 498-510).

32 PAVÍA (op. cit., pp. 81-85).

33 LLUIS I NAVAS (1972: 253); CARRIÓN (1973: 198).

34 MOYANO (1984: 130); I.C.A.V. (1986: 2).
} 
organismos encuadrados en dicha organización. Esto fue el paso previo a la elaboración de un Estatuto Fiscal de la Cooperación hecho realidad mediante el Decreto de 9 de abril de 1954. Un nuevo Estatuto se dicta por Decreto 881/1969, de 9 de mayo, en el que se establecían los requisitos necesarios a fin de que las cooperativas del campo pudieran ser clasificadas como protegidas a efectos fiscales (artículo $6^{\circ}$ ). Durante esta fase, el Estado estableció una serie de ayudas para las cooperativas del campo y grupos sindicales de colonización a través del Banco Hipotecario, el Servicio Nacional de Cereales, el Banco de Crédito Agrícola y otras instituciones ${ }^{35}$.

\section{Apertura al mercado exterior}

La mayoría de los autores coinciden en señalar que, superadas las difíciles circunstancias de la posguerra y repuesto su patrimonio, se inicia una etapa de fuerte crecimiento de las cooperativas del campo bajo el signo de la unidad, la espontaneidad y la ayuda mutua. No obstante, arrastra secuelas caciquiles que impiden la práctica democrática, así como un bajo nivel cultural entre sus miembros, y un cúmulo de enemistades vecinales que dificultarán la constitución de entidades de segundo grado ${ }^{36}$. El Plan de Estabilización de 1959 marca la divisoria entre dos etapas distintas del cooperativismo agrario: en la primera, todavía la actividad fundamental de éstas se orientará a la adquisición de los medios de producción; en la segunda, se encamina a la comercialización de los productos del campo, primero desde las instalaciones cooperativas y, más tarde, se irán estableciendo redes comerciales. A este fín, desde las UTECO, se promocionarán las Secciones de Crédito y la construcción de almazaras y bodegas cooperativas. Las presiones ejercidas desde distintos sectores a favor de la adecuación legal a las normas internacionales de la Cooperación dan un primer resultado positivo, cual es la publicación de un nuevo Reglamento por Decreto de agosto de 1971. Para Del Arco $^{37}$, esta disposición fortalece la cooperativa en cuanto empresa, interesando al socio en su desarrollo, regulando la formación de capital y reservas, permitiendo la asociación con entidades no cooperativas y la firma de conciertos entre éstas. Con posterioridad, la nueva Ley Sindical de 1971 modificó las competencias de la Organización Sindical atribuyéndole, ahora, el estímulo y desarrollo del movimiento cooperativo. En 1972 se crearon, por ley, las Agrupaciones de Productores Agrarios, copia de la ley francesa de 1962 por la que se creaban los groupements de producteurs, que usarán como sustrato jurídico la fórmula cooperativa o SAT. La reforma legislativa de los setenta culminará con la promulgación de la Ley 52/1974 General de Cooperativas, de 19 de diciembre y su Reglamento, aprobado por Decreto 2.710/1978, de 16 de noviembre, que abren el camino a un nuevo régimen jurídico al incorporar tanto los principios fundamentales aprobados por la A.C.I. en el Congreso de Viena de 1966, como determinadas experiencias legislativas procedentes de países miembros de la C.E.E.

A raíz de la publicación de estas normas, las antiguas UTECO se desdoblan en cooperativas de segundo grado, que continúan la actividad económica (principalmnte suministros), y permanecen las UTECO con carácter representativo provincial ${ }^{38}$. La multiplicación de

35 BORJABAD (1984: 99); PÉREZ TURRANO (1996: 79).

36 MATEO Y PALACIO (1972: 125); LLUIS I NAVAS (1972: 234); CARRIÓN (1973: 204-205).

37 Figura clave en el proceso de adaptación del Movimiento Cooperativo al Franquismo. Enviado por la Organización Sindical como jurista para incorporar la CONCA a la Obra Sindical de Cooperación; Vid. DEL ARCO ÁLVAREZ (1977: 12-14).

38 LLUIS I NAVAS (1972: 253); PÉREZ TURRANO (1996: 79); LLOBREGAT (1990: 101); MATEO y PALACIO (1972: 124-125); APARICIO (1947: 10); ROMERO (1981: 33-63). 
sociedades cooperativas es tal que, en 1970, en las tres provincias su número supera al de municipios, lo que acarrea una dispersión de la oferta en algunos sectores claves, como el del vino o el del aceite. A modo de ejemplo, entre 1958 y 1961 se produce la gran explosión en el sector vitivinícola creándose hasta 15 cooperativas en este cuatrienio, tantas como en los treinta años anteriores. Estas obras repercutirán en la mejora de la calidad aunque, en ocasiones, las cuantiosas inversiones provocaron la descapitalización de las sociedades más modestas. La agrupación comarcal o provincial no se pondrá en marcha hasta finales de los setenta con el fin de obtener una mayor productividad de las instalaciones y adecuar la calidad a los niveles exigidos por los mercados. En cuanto al sector hortofrutícola, en 1961, según Abad, sólo funcionaban siete cooperativas en la Plana de Castellón, no existiendo ni una sola en la provincia de Valencia. A finales de esta década, se acelera el proceso de creación de entidades, alcanzando las 80 en toda la Comunidad, en $1971^{39}$.

En el sector citrícola, tras la firma del Tratado Preferencial con la CEE se planteó llevar a cabo una asociación que representase los intereses del sector cooperativo ante el Comité de Gestión para la Exportación de Frutos Cítricos. Así, se constituyó, en 1972, el Grupo de Exportadores de Cooperativas Citrícolas y, a partir de esta experiencia nace, con carácter nacional, una de las entidades asociativas de segundo grado de mayor relieve, ANECOOP, S. COOP. que, tras la aprobación de sus Estatutos, en 1975, inicia la actividad exportadora con los cítricos comprometidos por las cooperativas asociadas. Ya en la siguiente campaña comienza a exportar junto a los cítricos, hortalizas, e irá incrementando tanto los volúmenes de productos como el número de cooperativas asociadas, por lo que, en 1977, se constituirá como cooperativa de segundo grado, iniciando una carrera imparable en el control del mercado nacional e internacional.

\section{Expansión del sector financiero cooperativo}

Con la ampliación de la actividad comercial, las Cajas Rurales vuelven a resurgir y se hace necesaria la regulación del sector financiero. Así, la Ley 2/1962 de Bases de Ordenación del Crédito y la Banca ordenó la creación del Banco de Crédito Agrícola tanto tiempo demandado por el sector. En 1964, se publica el Decreto 716/1964, de 26 de marzo, dedicado exclusivamente a reglamentar el crédito cooperativo para que sirviera a la política económica general; en este texto se definía a la Caja Rural como una sociedad cooperativa sin carácter lucrativo ${ }^{40}$, asignando a la Caja Rural Nacional funciones de coordinación de las otras Cajas, y de representación ante el Ministerio de Hacienda. Ese mismo año, una Orden de 17 de noviembre establecía en 5 millones de pesetas el volumen de recursos necesarios para que una Caja Rural Provincial o Local pudiera obtener el título de Caja Rural Calificada, autorizada para la distribución del crédito oficial. Con esta legislación, el sistema de Cajas Rurales quedó organizado territorialmente en Cajas Rurales de ámbito local que podían disponer de Secciones de Crédito o de Cooperativas de Crédito; las Cajas Rurales Provinciales, que asociaban a las cajas locales de la provincia, y la Caja Rural Nacional, que asociaba, de manera voluntaria, a las provinciales. Por último, en 1970, por Orden del Ministerio de Trabajo, se creará la Unión Nacional de Cooperativas de Crédito.

La red de Cajas de la Comunidad fue expandiéndose y, en 1972, Castellón contaba con 36 entidades locales y comarcales adheridas a dicha institución que reunían unos depósitos de 3.593 millones de pesetas. Valencia disponía de 17 Cajas y unos fondos de 1.335 millones de pesetas. Alicante contaba con 2 entidades pertenecientes ambas a Orihuela,

39 ABAD (1991: 115); CARRIÓN (1973); CABALLER et al. (1987: 31); SANZ JARQUE (1974: 277 288).

40 RODERO (1987: 145). 
con unos depósitos de 1.172 millones de pesetas, además de los depósitos de las Cajas Rurales Provinciales. En la década de los setenta el movimiento cooperativo gozaba de buena salud y pasará a convertirse en el primer intermediario financiero del sector agrario español con la Administración, al amparo de los profundos lazos que la ligaban con los rectores de la Caja Rural Nacional ${ }^{41}$. Pero esta organización presentaba ciertas dificultades estructurales para su desarrollo, frente a lo cual se van manifestando dos tendencias: una defensora de la centralización y, otra. partidaria de una estructura federativa. La división se hará evidente tras la firma, en 1974, de un Consorcio Nacional entre 38 Cajas Rurales Provinciales en el seno de la Caja Rural Nacional, relegando, así, a las Cajas de ámbito menor.Tres años más tarde, aprovechando la promulgación de la Ley 19/1977 de Libertad Sindical, se convocaron unas Jornadas de Estudio para la Promoción de las Cajas Rurales, en Viella, a las que acudieron varias Cajas de Valencia y de Alicante. Estos encuentros finalizarán con una declaración programática en la que se proclama el derecho de las Cajas Rurales de España a participar en la elaboración de leyes y disposiciones encaminadas a regular su funcionamiento y competencias. Paralelamente se pide la agrupación de todas las cooperativas de crédito en un ente o entes territoriales, convergentes a escala nacional, entre otras cuestiones, al tiempo que se nombra una Comisión para que las represente y negocie ante la Administración.

Al no dar resultado las conversaciones con el gobierno, se incia la ruptura con la formación de la Agrupación Arca de Cajas Rurales de España Sociedad Cooperativa, en la que se integran 31 entidades comarcales y locales. La publicación del Real Decreto 2.860/78, que estableció los principios a los que debían ajustarse dichas instituciones, así como la homologación de éstas con las restantes entidades de crédito, supondrá el cambio de nombre a Consorcio Español de Cajas Rurales (CECAR) y la modificación de sus Estatutos (febrero de 1980) para convertirse en una cooperativa de segundo grado. Al año siguiente, el grupo CECAR creó una entidad financiera nacional, la Central de Cajas Rurales y, en julio de 1982, la entidad representativa del Grupo, la Unión de Cooperativas de Cajas Rurales Comarcales y Locales. En poco más de diez años (1971-1983), el capital social de las Cajas Rurales se había incrementado en un 757 por ciento, y las reservas en un 7.242 por ciento, según Martín Mesa.

A principios de 1983, se contabilizaban 128 Cajas Rurales a escala nacional, de las cuales 2 eran de ámbito nacional, 49 provinciales, 11 comarcales y 66 locales, organizadas en varias agrupaciones: por una parte, el grupo CRUNA en torno a la Caja Rural Nacional; el grupo CECAR formado por la Central de Cajas Rurales; el Consorcio Levantino constituído por 10 entidades de ámbito comarcal y local; por último, un Consorcio Provincial formado por la Caja Rural de Castellón con sus Cajas asociadas. La crisis de 1982 se saldará con la firma, en julio del 93, del Acuerdo Marco para constituir el Grupo Asociado BCA-CRA, en el que se contemplaba la realización de auditorías y el diseño de Planes de Saneamiento de las entidades aspirantes, con carácter previo a la asociación ${ }^{42}$.

\section{Proceso descentralizador del sector agrario valenciano}

Tras la promulgación de la Contitución de 1978, el proceso autonómico comenzó su andadura en el campo cooperativo; el Ministerio de Trabajo emprendió la descentralización en el sistema de registro. En 1980, aún se presenta un proyecto de Ley de Cooperativas que no salió adelante. Al año siguiente se aprueba, por Real Decreto 1776/1981, de 3 de agosto,

41 MARTÍN (1988: 268).

42 VICENTE (1991: 522-523); MARTÍN (1988: 275-276), enumera las causas de esta crisis. CARRIÓN (1973: 202-204). CRUZ (1977: 191-216). 
el Estatuto de las Sociedades Agrarias de Transformación (SAT), nombre con el que se designarán, a partir de entonces, los antiguos Grupos Sindicales de Colonización, fórmula que sólo podrá ser utilizada para fines agrarios y sus asociados han de ser, necesariamente, titulares de explotaciones agrarias, trabajadores agrícolas o personas jurídicas asociadas con fines agrarios ${ }^{43}$. A finales de 1982, el número de sociedades inscritas en el registro general de SAT ascendía a 4.219, de las cuales 3.413 eran sociedades preexistentes que adaptaron sus estatutos, y 809 sociedades de nueva creación. La Comunidad Valenciana contaba con 647 SAT, integradas por 65.115 socios, lo que la situaba en cabeza en relación al resto de comunidades autónomas y, en cuarto lugar, por volumen de capital. Ese mismo año, Ley 1/82, de 11 de febrero, de Cooperativas del País Vasco abrió la primera vía hacia un diseño de organización cooperativa descentralizado ${ }^{44}$, al que le siguieron, la Ley de Cooperativas de Cataluña de 9 de marzo de 1983, la de Andalucía (Ley 2/1985, de 2 de mayo) y, en cuarto lugar, la Ley 11/1985, de 25 de octubre, de Cooperativas de la Comunidad Valenciana.

En la Comunidad, el proceso para la transferencia de competencias se inicia con el Decreto 45/1984, de 16 de abril, del Consell de la Generalitat Valenciana, por el que se crea el Instituto de Cooperativismo Agrario, como un servicio, con sede en Valencia, dependiente a todos los efectos de la Conselleria de Agricultura i Pesca, siendo conseller el expresidente de UTECO-Valencia, Luis Font de Mora, y bajo cuya influencia se redactará la primera ley de cooperativas valencianas. Entre los órganos de gobierno de este servicio se hayan el Consejo General y el Consejo Ejecutivo. En el primero se integran, como vocales, un grupo destacado de personajes rectores del cooperativismo valenciano de los años ochenta; sin embargo, en el Ejecutivo, apenas si estaban representadas las Organizaciones Profesionales y Cooperativas. Para llevar a la práctiva los objetivos de la política autonómica, en materia cooperativa, el Consejo General diseñó una serie de Programas y estableció subvenciones. A su vez, el Instituto de Cooperativismo Agrario (I.C.A.V.), con el Instituto de Relaciones Agrarias y el Servicio de Extensión Agraria, elaboraron un Directorio de Entidades Asociativas Agrarias de la Comunidad Valenciana. La distribución de cooperativas y socios por provincias, ante el traspaso de competencias, queda reflejada en el cuadro adjunto.

\section{EL SECTOR AGRARIO VALENCIANO}

\begin{tabular}{|l|c|c|c|c|}
\hline & $\begin{array}{c}\text { COOP } \\
\mathbf{1}^{\mathbf{0}} \text { GRADO }\end{array}$ & SOCIOS & $\begin{array}{c}\text { COOP } \\
\mathbf{2}^{\mathbf{0}} \text { GRADO }\end{array}$ & SOCIOS \\
\hline CASTELLÓN & No constan & 75367 & 1 & 104 \\
\hline VALENCIA & 286 & 143101 & 11 & 510 \\
\hline ALICANTE & 135 & 100544 & 5 & 131 \\
\hline COM. VALENCIANA & 563 & 319012 & 17 & 745 \\
\hline
\end{tabular}

Fuente: Conselleria d'Agricultura i Pesca, 1985.

Conocido el borrador de la futura ley, las UTECO provinciales iniciaron la preparación de un Congreso que se celebrará en Benidorm, del 19 al 21 de diciembre de 1984, al que asistieron más de 750 cooperativistas; los acuerdos fueron publicados en la revista Agricul-

43 BEL DURÁN (1997: 118); GONZÁLEZ PINILLA (1995: 21-23); CASTAÑO (1996: 42-45).

44 LLOBREGAT HURTADO (1990: 114); La Constitución estableció en el artículo 129.2: Los poderes públicos promoverán eficazmente las diversas formas de participación en las empresas y fomentarán, mediante la legislación adecuada, las sociedades cooperativas. Esta prescripción se completa con la cláusula residual contenida en el artículo 149.3, según la cual las materias no expresamente atribuidas al Estado por la Constitución podrán corresponder a las Comunidades Autónomas; SÁNCHEZ BLANCO (1982: 9-20; BONET et al. (1989: 18). 
tura y Cooperación, resumidos en 10 puntos, a modo de mandamientos ${ }^{45}$. El texto definitivo de la Ley recogió algunas de las propuestas hechas por el Congreso, en su totalidad o en parte, buscando el consenso. Este mismo año, como consecuencia del creciente número de cooperativas y SAT que obtenían la calificación APA (Asociación de Productores Agrarios), nace la Asociación Regional Valenciana (ARVAPA) con el fin de aportar una sólida representación en la Federación Española de Agrupaciones de Productores Agrarios (FEAPA).

La Ley 11/1985, de 25 de octubre, supuso la plasmación de la competencia exclusiva en materia de legislación cooperativa de los poderes autonómicos valencianos, reconocida en el Estatuto de Autonomía con carácter general en el artículo 31, apartado 2.1, y en materia de instituciones de crédito cooperativo (artículo 34, apartado 1.6). El punto más polémico, con mucho, fue la incorporación a la definición de cooperativa del concepto sin ánimo de lucro, que había sido suprimido en la ley general de cooperativas de 1974 y en el resto de legislaciones autonómicas por ser una reminiscencia de la ley franquista de $1954^{46}$. Tras la publicación de la Ley se darán un conjunto de normas por las que se regulan las Cooperativas de Crédito (Decreto 8/1986, de 10 de febrero), se crea el Instituto de Promoción y Fomento del Cooperativismo (Decreto 135/1986) que asume gran parte de las competencias del I.C.A.V.. Posteriormente, el Consejo Superior del Cooperativismo se regula por Decreto 170/1986, asumiendo las competencias del, hasta entonces, Consell Asesor de Cooperatives, quedando adscrito a la Conselleria de Treball i Seguretat Social.

La organización del Cooperativismo agrario valenciano contemplada por la Ley quedará integrada por las cooperativas de primero y segundo grado, las Uniones Provinciales de Cooperativas (UTECO) de Castellón, Valencia y Alicante, más la Federación Valenciana de Cooperativas Agrarias ${ }^{47}$. A escala nacional, esta organización forma parte de UCADE o Unión de Cooperativas Agrarias de España y de la Confederación Española de Cooperativas Agrarias, que, a su vez, se organiza con las demás Confederaciones de países miembros de la Unión Europea dentro del CO.CE.GA. (Comité General de la Cooperación Agrícola de la Comunidad Europea).

Transcurrida una década desde la entrada en vigor de la primera Ley de Cooperativas Valencianas, el marco legal autonómico se verá sustancialmente modificado mediante la Ley 3/1995, de 3 de marzo, de Cooperativas de la Generalitat Valenciana, refundida por el Decreto legislativo 1/1998, de 23 de junio del Gobierno Valenciano. Entre las modificaciones esenciales, el artículo 49.2 incrementó hasta 500.000 pesetas la cantidad mínima necesaria para constituir una cooperativa. Con la nueva norma, los Estatutos podrán fijar si la cuantía será igual para todos los socios o proporcional a su actividad cooperativizada desarrollada o comprometida, hasta cubrir la cantidad exigida. Además, el asociado podrá tener hasta un $45 \%$ de voto o de participación en el Capital Social y formar parte del Consejo Rector. Aunque la principal novedad estaba en el texto del artículo $65^{\circ}$ que recogía la posibilidad de transformar la cooperativa en otra figura societaria ${ }^{48}$.

\section{Integración en el mercado común europeo}

La adhesión de España a la Comunidad Europea, efectiva desde el 1 de enero de 1986, tuvo una gran repercusión económica, social y política en España. Para la Comunidad Valenciana supuso la integración en una red de mercados cuyas bases presuponían la desaparición de barreras aduaneras o de otro tipo de restricciones al comercio entre los países

45 Ley 11/1985 de 25 de octubre, Valencia, Conselleria de Treball i Afers Socials, 1986, n 21, 1985.

46 Agricultura y Cooperación, $\mathrm{n}^{\mathrm{o}}$ 30, 1985, p. 7.

47 I.P.F.C. (1992); JULIÁ y SEGURA (1986: 13-14); BONET et al. (1989: 13-19); I.P.F.C. (1988: 6-7)

48 PASTOR (1999); LLOBREGAT (1999). 
miembros; la igualdad en cuanto a las formas y niveles de protección en el comercio exterior; la armonización de las legislaciones o políticas nacionales que pudieran repercutir en las condiciones de competencia, así como la equiparación de los precios y ayudas institucionales que afectan a la producción y al comercio agrícola ${ }^{49}$. Todo un proceso revolucionario en el terreno legislativo se pone en marcha.

La armonización de las políticas agrarias se inicia con la promulgación de nuevas normas jurídicas para adaptar la legislación española a las normas y figuras comunitarias. Entre éstas cabe destacar, el R.D. 1101/1986, de 6 de junio, que regula la constitución de las Organizaciones de Productores de Frutas y Hortalizas (OPFH). El R.D. 2340/1986, de 19 de septiembre, desarrolla el Reglamento (CEE) 1035/1972 y viene a regular el mercado de frutas y hortalizas, otorgando a las APA-OPFH la capacidad legal para retirar productos del mercado. Mediante el R.D. 2796/1986, de 19 de diciembre, se desarrolla el Reglamento (CEE) 136/1966, del Consejo de 22 de septiembre, y establece el procedimiento para reconocer a las Organizaciones de Productores de aceite de oliva y sus Uniones, las cuales permiten la institucionalización de las ayudas a la producción. La Orden de 1 de diciembre de 1988 crea el Registro General de Agrupaciones de Productores y sus Uniones.

Mediante la Política Agraria Común se ha establecido un nivel uniforme de precios y ayudas dentro del mercado europeo, de los que se beneficiron los agricultores españoles. Los instrumentos para su aplicación han sido lo que se conoce como Organizaciones Comunes de Mercado $(\mathrm{OCM})^{50}$. Para una serie de productos agrícolas básicos (cereales, lácteos, azúcar, carnes bovina y ovina...) esas organizaciones han supuesto la garantía de compra pública a unos precios instituídos, si el mercado no pudiera absorberlos a un precio superior, y la paralela protección en el comercio exterior de esos niveles de garantía interna. A su vez, las organizaciones de mercado de algunos productos (aceite de oliva, granos oleaginosos, tabaco) han establecido ayudas y subvenciones a la producción, comercialización o para su transformación industrial, permitiendo precios relativamente bajos en su consumo o como materias primas. En otros productos como frutas y hortalizas, vino... la intervención ha sido más débil u ocasional. Estos sistemas han contribuido a sostener las rentas agrícolas, a estabilizar los mercados y mejorar las tasas de autoaprovisionamiento de la U.E.

Pero el coste de la PAC, y en concreto de las organizaciones comunes de mercado agrícolas, suponía el grueso del gasto de la UE, aunque ha sufrido un fuerte recorte, no sólo por exigencias internas sino, más bien, por presiones externas. Así, entre 1968 y 1975, el gasto agrícola supuso aproximadamente en torno al 72 y el 93 por ciento del presupuesto comunitario. Pero, desde 1976, el porcentaje se situó entre el 60 y el 75 por ciento. Ya en el presupuesto general de 1991, descendió hasta aproximarse al 57 por ciento, y en el de 1996 se redujo al 48 por ciento. De acuerdo con las negociaciones del GATT, el descenso debe continuar. Además, las ayudas han variado cualitativamente: hasta 1992, el 90 por ciento de las ayudas eran subvenciones directas a la producción; en el 2000, el 10\% se destinaba a desarrollo rural, el $20 \%$ a ayudas directas, y el $70 \%$ se convirtieron en subvenciones a la producción en pagos por hectárea cultivada o por cabeza de ganado, no por kilo producido. Este es el camino emprendido con la reforma de 1992, y la Agenda 2000 continúa en esta línea de hacer un pago desvinculado de la producción.

La Agenda 2000 (PAC III), aprobada en el Consejo Europeo de Berlín, celebrado entre el 24 y 26 de marzo de 1999, marcó las pautas a seguir hasta 2006; introdujo un modelo de agricultura familiar basado no sólo en la competitividad como primer pilar, sino tam-

49 TAMAMES et al. (1966: 11-27); ZAMARRIEGO et al. (1996: 50-70); FERNÁNDEZ (1998: 5-17); KELLNER (1985: 74-80). 29).

50 WIEIDENFELD y WESSELS (1997: 190); JULIÁ y SERVER (1990: 70-75); BOTELLA (1972: 12- 
bién en el desarrollo rural y la conservación de la naturaleza ${ }^{51}$. El elemento básico de esta reforma es la reducción de los precios de garantía de los productos agrarios de la UE para acercarlos a las cotizaciones internacionales. La contrapartida a la reducción de los precios de intervención es el aumento de los pagos compensatorios que ahora pasan a llamarse ayudas directas, aunque introduciendo una serie de elementos para facilitar su legitimación. Los principales conceptos que el documento Agenda 2000 proponía incorporar a la futura política agroambiental de la UE, y que han sido aprobados, son los siguientes:

- Permitir a los Estados miembros la introducción de condiciones medioambientales cuyo cumplimiento sería requisito obligado para percibir los pagos compensatorios .

- Transformar gradualmente el sistema actual de indemnizaciones compensatorias a las explotaciones situadas en zonas de agricultura de montaña y desfavorecidas en un instrumento para mantener sistemas agrarios intensivos.

- Incrementar el presupuesto destinado a ayudas agroambientales (Reglamento 2078/92), aumentando, cuando sea necesario, la tasa de cofinanciación comunitaria; la contrapartida a esta propuesta sería la exigencia de un mayor rigor en el planteamiento, aplicación, control y evaluación de los programas agroambientales a los Estados miembros. Según la Comisión, se trataría de centrar los programas en agricultura ecológica, mantenimiento de hábitats y ecosistemas, etc.

Por lo que se refiere a España, es evidente que se ha dado un paso de gigante en la equiparación de las condiciones de producción en la agricultura española a la de los restantes países de la Unión. España se ha beneficiado, junto a Irlanda, Grecia y Portugal del Fondo de Cohesión, creado en 1993, que aportó una contribución financiera a proyectos relacionados con el medio ambiente y las infraestructuras del transporte para reducir las divergencias entre las economías de los países miembros. Además, han llegado ayudas del FEDER para financiar proyectos de desarrollo regional en áreas rurales especialmente deficitarias en infraestructuras o con proyectos, repercutiendo en el aumento de la calidad de vida y de las rentas indirectas de los propietarios de estos espacios.

El reconocimiento de las entidades asociativas como elementos básicos de regulación de los mercados agrarios ha sido determinante para el desarrollo económico experimentado por el cooperativismo agrario en la década 1990-2000. Al iniciarse los noventa existían en España cerca de 4.000 cooperativas, con 250 millones de facturación media y un volumen global de negocio superior a medio billón de pesetas. En el 2000, el cooperativismo agrario era el mayor grupo alimentario del país (comercializan el $80 \%$ de la producción aceitera, al menos a nivel primario; el $60 \%$ del vino y el $45 \%$ de la fruta fresca), con intereses diversos pero, también, con objetivos comunes. La Comunidad Valenciana ocupa el cuarto lugar en cuanto a número de empresas de primer grado. Sin embargo, mantiene el liderazago en cooperativas de segundo grado; no obstante, la dispersión geográfica sigue siendo un factor negativo en la coordinación interna. No hay que olvidar, dice Juliá Igual ${ }^{52}$, que la pertenencia a estructuras de segundo grado, desde la perspectiva empresarial, ha permitido el desarrollo cooperativo de forma más eficaz, dadas las economías de escala que se derivan de dicho proceso y, para Caballer, en los tiempos que corren, el cooperativismo agrario será integrador y universal o no será. En esta dirección se han ido creando dentro de las cooperativas nuevas secciones de comercialización, de transformación, de Turismo Rural, de Plantas Aromáticas... Aunque, en las cooperativas levantinas, la sección de comercialización hortofrutícola suele ser la más importante, la que ocupa una mayor superficie en el conjunto de las instalaciones cooperativas.

51 VELARDE (1999: 3-8).

52 JULIÁ (1989: 62). 
Las actividades integradas en grupos cooperativos (ANECOOP, UTECO) han motivado la creación de empresas en las que participan las cooperativas mayoritariamente, junto a entidades públicas y privadas, al igual que antes hicieron otras cooperativas europeas. Así surgieron: Agrocalidad, empresa en la que participan cooperativas con el $51 \%$ de capital a través de sus cooperativas provinciales de suministros de segundo grado (Valencia, Navarra, Castellón...) y el grupo INAGRA; otro grupo de este tipo es Agricultura y Conservas S.A., fundado en 1990, con capital aportado por ANECOOP, la Generalitat Valenciana, además de un grupo de cooperativas hortofrutícolas. Experiencias similares se han puesto en práctica en este sector, en el olivarero, en el de frutos secos, etc., siguiendo la recomendación que daba ya, en 1989, Ramón Salabert ${ }^{53}$, de colaborar con Europa al tiempo que nos hacemos fuertes dentro, para no acabar vendiendo nuestras entidades a las multinacionales cooperativas, o evitar convertirnos en empresas auxiliares de ellas.

En este punto es esencial el apoyo que prestan las Cajas Rurales y las propias Secciones de Crédito de las cooperativas. Para responder a las necesidades de intercooperación de éstas, en 1987, se constituyó la Federación de Cajas Rurales Cooperativas de Crédito de la Comunidad Valenciana que, tras diez años de funcionamiento, contaban, en 1997, con 41 Cajas Rurales asociadas, la totalidad del sector, a través de las repectivas Uniones Provinciales: a Alicante correspondían 6 Cajas; la Unión de Castellón estaba integrada por 23; la Unión de Valencia, $12^{54}$. Según la Federación Valenciana, el 50\% de las Cajas Rurales Cooperativas de Crédito del conjunto del Estado se había desarrollado en nuestra Comuni$\operatorname{dad}^{55}$. El Grupo Caja Rural se integró, en 1998, en el grupo europeo «Unic Banking Grup», constituído por bancos cooperativos de nueve países europeos, destacando el Robobank en los Países Bajos, el Crèdit Agrícole Mutuel en Francia o el sistema de banca cooperativa alemán Volksbanken-Raiffeisenbanken ${ }^{56}$. La apuesta para el futuro, según el criterio de Luís Juarez, entonces presidente, estaba en la captación de clientes en los núcleos urbanos contando con las especificidades de este Grupo, resumidas en los términos siguientes: la tradición democrática de la Banca Cooperativa Europea, el contacto cotidiano (banca de proximidad) con los problemas económicos y empresariales del entorno en el que opera; la posibilidad de manejar los tipos y precios de manera más flexible, puesto que no han de retribuir al accionista, y el hecho de que una parte de los resultados revierte a la sociedad a través del Fondo de Educación y Promoción.

Con fecha 26 de febrero de 2002, las Asambleas Generales de las Cajas Rurales de Valencia, Alicante y Credicoop (Castellón) aprobaron, por unanimidad, su fusión, con efectos retroactivos al uno de enero, en la Caja Rural del Mediterráneo-Ruralcaja Sociedad Cooperativa de Crédito, mediante un proceso de fusión por absorción, en el que Caja Rural Valencia absorbe a las otras dos entidades (Credicoop no integra a sus once Cajas Rurales, sino sólo a la matriz de la cooperativa de segundo grado) y, posteriormente, se transforma en la nueva Caja para lograr ahorros importantes ${ }^{57}$. Ruralcaja tendrá un sólo Consejo de Administración, presidido por Luis Juárez (Valencia), el gran impulsor del proceso, un vicepresidente primero de Credicoop, y un vicepresidente segundo de Alicante. La nueva organización contemplaba tres Zonas de Interés Económico y Social (ZIES) con comités territoriales que pueden tomar decisiones hasta determinadas cuotas de negocio. Ruralcaja nace con una plantilla de 1.400 empleados, 390 oficinas, unos recursos propios de 213

53 Director General de Cooperativas y Sociedades Laborales.

54 FEDERACIÓN DE CAJAS RURALES (1988: 11); CAJA RURAL DE CASTELLÓN (1997: 42).

55 GRUPO CAJA RURAL (1996: 12).

56 MONTERO (1996: 83), afirma que el sector del cooperativismo de crédito controla el 20\% del ahorro europeo.

57 Diario El Mundo, 27 de febrero de 2002. 
millones de euros y se convertirá en la segunda de España, tras Cajamar (Cajas de Málaga y Almería unidas).

\section{Conclusiones}

La red de cooperativas agrarias actual en la Comunidad Valenciana se fue conformando desde mediados del siglo XIX. Los primeros ensayos se dieron en los núcleos urbarnos con un amplio hinterland agrario. El modelo de cooperativa originaria fue la de consumo, inspirada en los Principios cooperativos de Rochdale, para distribuír entre sus socios: herramientas, granos, abonos, semillas, animales y hasta productos alimenticios en condiciones determinadas. En la última década de este siglo se organizan, también, las primeras cooperativas de crédito; éstas, al contrario que las de consumo, tienden a organizarse en las comarcas con agricultura de secano. Las primeras experiencias las llevan a cabo exiliados republicanos, propagandistas del movimiento, valiéndose de instituciones como la Sociedad de Amigos del País de Valencia. Las Cámaras Agrarias, a partir de 1890, van a jugar un papel destacado en la promoción del asociacionismo entre pequeños y medianos propietarios a escala regional y nacional.

La crisis finisecular da lugar a graves conflictos sociales entre grandes propietarios y obreros. El movimiento obrero responde, especialmente en las ciudades, afiliándose a organizaciones anarquistas o socialistas. En este contexto el P.Vicent, desde el colegio San José de Valencia, ve frenada su labor de difusión gremial y cooperativa, por lo que llevará la acción al medio rural, entre las clases pudientes (socios protectores) y los obreros agrícolas, que aún siguen siendo fieles a la Religión. A partir de 1906, defenderá con mayor ahinco la autonomía económica de la organización sindical. Su gestión inspira la Ley de Sindicatos Agrícolas de 1906, que establece los pilares de la cooperación agraria en España. El cooperativismo católico se extenderá rápidamente desde la ciudad de Valencia a todos los pueblos de la Huerta, por la Safor, la Marina Alta, la Vega Baja, etc., actuando, como señala Garrido, como eje de vertebración y de articulación del mundo rural.Como la normativa vigente prohibía la fundación de más de un sindicato por localidad, católicos, socialistas y anarquistas se van a disputar el apoyo y fomento de las cooperativas. Aunque con el tiempo convergen en la defensa común de una legislación favorable al movimiento cooperativo.

El Primer Congreso Nacional de Cooperativas, celebrado en el paraninfo de la Universidad de Barcelona, en 1913, por iniciativa de la Cámara Regional de Cataluña y Baleares, marca el inicio de la política de acercamiento. Otro hito destacado es la elaboración del Anteproyecto de Ley de Cooperativas de 1927, por una comisión coordinada por Gascón y Miramón. Estos encuentros propiciaron la creación de una Federación Nacional de Cooperativas, en 1928, en base al acuerdo de que dicha asociación no se ocuparía de política ni de religión al considerar la cooperación como un terreno neutral. La crisis de 1929 acarrea la pérdida de influencia de los católicos en el mundo agrario frente a socialistas y anarquistas. No obstante, los sindicatos agrícolas continuarán alejados de la Administración y bajo la tutela de la Iglesia Católica. En 1932, cuando se celebró en Bilbao el cuarto Congreso Nacional de Cooperativas se puso de manifiesto esta divergencia. Iniciada la guerra civil Vicente Uribe, al frente del Ministerio de Agricultura, inicia una política favorable a la creación de cooperativas en los pueblos, provocando que colectividades preesistentes se transformen para conseguir las ayudas. Es por ello que, antes de terminar la guerra, Franco decretó la confiscación de todos los bienes y efectos pertenecientes a determinadas Organizaciones Sindicales en beneficio de Falange. En la Comunidad Valeniana afectó a una veintena de ellas. 
La Ley de Unidad Sindical, de 26 de enero de 1940, derogó la Ley de Cooperación de 1938 y, con ella, la práctica democrática del sistema. Por Orden de 11 de junio de 1941, el gobierno militar determinó, a su vez, que las agrupaciones debían adoptar la denominación de Grupos Sindicales si querían percibir las ayudas contempladas por la ley. Tres meses más tarde, se derogaba la Ley de Sindicatos Agrícolas de 1906 y se integraba en la Organización Sindical a todos los Sindicatos, sus Federaciones y Confederaciones. Al finalizar la guerra también verán bloqueadas sus cuentas algunas colectividades o cooperativas agrarias.

La Ley de 2 de enero de 1942 abre otro período del cooperativismo agrario valenciano (primera norma legal que concede entidad propia a las Cooperativas del Campo).Mediante esta norma las cooperativas son incorporadas a la Organización Sindical del Movimiento, al tiempo que se crea la Obra Sindical de Cooperación, dependiente del Ministerio de Trabajo. Pero, lo que determinó la liquidación definitiva de la CONCA (Confederación Nacional de Sindicatos Católicos Agrarios) y, con ella, la organización independiente del cooperativismo agrario, fue la publicación de la Ley de Unidad Sindical Agraria, en el B.O.E. del 8 de agosto de 1944, y su Reglamento, de 1945. El cooperativismo valenciano, en la posguerra, era prácticamente inexistente. El estallido de la Segunda Guerra Mundial frenó la importación de productos nitrogenados para la producción de abonos y la paralización de las cooperativas llegaría a su punto máximo en 1954.Para paliar esta situación, desde el Estado se distribuyeron ayudas a través del Banco Hipotecario, el Servicio Nacional de Cereales y otras instituciones.

El Plan de Estabilización de 1959 abre una nueva etapa.La actividad de las cooperativas se orienta hacia la comercialización de los productos del campo, primero desde las instalaciones cooperativas y, más tarde, a través de la creación de redes comerciales. En esta etapa, la multiplicación de entidades cooperativas, con las ayudas del Estado, se convierte en un problema porque acarrea una dispersión de la oferta en algunos sectores claves, como el del vino o el del aceite.Conscientes, entonces, de la necesidad de unir fuerzas para mantener precios y calidades, en 1972, se constituyó el Grupo de Exportadores de Cooperativas Citrícolas y, a partir de esta experiencia nace, con carácter nacional, una de las entidades asociativas de segundo grado de mayor relieve, ANECOOP, S. COOP., que inicia su actividad exportadora a partir de 1975. Paralelamente, las presiones ejercidas desde distintos sectores a favor de la adecuación legal a las normas internacionales de la Cooperación, dan un primer resultado positivo, cual es la publicación de un nuevo Reglamento por Decreto de agosto de 1971. Este proceso culmina con la Ley 52/1974 General de Cooperativas, de 19 de diciembre y su Reglamento, aprobado por Decreto 2.710/1978, de 16 de noviembre, que abren el camino a un nuevo régimen jurídico al incorporar tanto los principios fundamentales aprobados por la A.C.I., como determinadas experiencias legislativas procedentes de países miembros de la C.E.E.

La actividad comercial genera beneficios que son canalizados a través de las Cajas Rurales. Mediante el Decreto 716/1964, de 26 de marzo, se reguló el crédito cooperativo. En este texto se definía a la Caja Rural como una sociedad cooperativa sin ánimo de lucro. una Orden de 17 de noviembre establecía en 5 millones de pesetas el volumen de recursos necesarios para que una Caja Rural Provincial o Local pudiera obtener el título de Caja Rural Calificada, autorizada para la distribución del crédito oficial. Con esta legislación, el sistema de Cajas Rurales quedó organizado territorialmente en Cajas Rurales de ámbito local que podían disponer de Secciones de Crédito o de Cooperativas de Crédito; las Cajas Rurales Provinciales, que asociaban a las cajas locales de la provincia, y la Caja Rural Nacional. Por último, en 1970, por Orden del Ministerio de Trabajo, se creará la Unión Nacional de Cooperativas de Crédito. En la década de los setenta el movimiento cooperativo gozaba de 
buena salud y pasará a convertirse en el primer intermediario financiero del sector agrario español con la Administración.

Pero el modelo de organización financiera va a entrar en crisis en los años finales de la Dictadura. De ella surgió, en 1980, el Consorcio Español de Cajas Rurales (CECAR), cooperativa de segundo grado y, al año siguiente, una entidad nacional, la Central de Cajas Rurales. En poco más de diez años (1971-1983), el capital social de las Cajas Rurales se había incrementado en un 757 por ciento, y las reservas en un 7.242 por ciento, según Martín Mesa. La crisis de 1982 se saldará con la firma, del Acuerdo Marco para constituir el Grupo Asociado BCA-CRA, en el que se contemplaba la realización de auditorías y el diseño de Planes de Saneamiento de las entidades aspirantes, con carácter previo a la asociación.

La Ley 1/82, de 11 de febrero, de Cooperativas del País Vasco abrió la primera vía hacia un diseño de organización cooperativa descentralizado, al que le siguieron, la Ley de Cooperativas de Cataluña de 9 de marzo de 1983, la de Andalucía (Ley 2/1985, de 2 de mayo), y, en cuarto lugar, la Ley 11/1985, de 25 de octubre, de Cooperativas de la Comunidad Valenciana. En la Comunidad Valenciana, el proceso para la transferencia de competencias se inicia con el Decreto 45/1984, de 16 de abril, del Consell de la Generalitat Valenciana, siendo conseller el expresidente de UTECO-Valencia, Luis Font de Mora, y bajo cuya influencia se redactará la primera ley de cooperativas valenciana. El texto definitivo de la Ley recogió algunas de las propuestas hechas por el Congreso de las UTECO, celebrado en Benidorm. Esta Ley supuso la plasmación de la competencia exclusiva en materia de legislación cooperativa de los poderes autonómicos valencianos, reconocida en el Estatuto de Autonomía con carácter general, y en materia de instituciones de crédito cooperativo. El punto más polémico, con mucho, fue la incorporación a la definición de cooperativa del concepto sin ánimo de lucro, que había sido suprimido en la ley general de cooperativas de 1974 y en el resto de legislaciones autonómicas.Transcurrida una década desde la entrada en vigor de la primera Ley de Cooperativas Valencianas, el marco legal autonómico se verá sustancialmente modificado mediante la Ley 3/1995, de 3 de marzo, de Cooperativas de la Generalitat Valenciana,

La adhesión de España a la Comunidad Europea, al año siguiente, supuso la integración en una red de mercados cuyas bases presuponían: la desaparición de barreras aduaneras o de otro tipo de restricciones al comercio entre los países miembros; la igualdad en cuanto a las formas y niveles de protección en el comercio exterior; la armonización de las legislaciones o políticas nacionales que pudieran repercutir en las condiciones de competencia, así como la equiparación de los precios y ayudas institucionales que afectaran a la producción y al comercio agrícola. La armonización de las políticas agrarias se inicia con la promulgación de nuevas normas jurídicas para adaptar la legislación valenciana a las normas y figuras comunitarias. La nueva legislación se encamina a regular la constitución de las Organizaciones de Productores de Frutas y Hortalizas, a establecer el procedimiento para reconocer a las Organizaciones de Productores de aceite de oliva y sus Uniones, a integrar las organizaciones regionales españolas en las organizaciones de mercado europeas, a difundir las normas y ayudas a la producción y distribución que exige este mercado. Hay que tener en cuenta que las organizaciones de mercado de algunos productos (aceite de oliva, granos oleaginosos, tabaco) habían establecido ayudas y subvenciones a la producción, comercialización o para su transformación industrial. En otros productos como frutas y hortalizas, vino... la intervención fue más débil u ocasional, a fin de sostener las rentas de los agricultores, estabilizar los mercados y mejorar las tasas de autoaprovisionamiento de la Unión Europea.

El reconocimiento de las entidades asociativas como elementos básicos de regulación de los mercados agrarios españoles ha sido determinante para el desarrollo económico experimentado por el cooperativismo agrario en la década 1990-2000. En el 2000, era el 
mayor grupo alimentario del país (comercializaban el $80 \%$ de la producción aceitera, al menos a nivel primario; el $60 \%$ del vino y el $45 \%$ de la fruta fresca), con intereses diversos aunque objetivos comunes.

Pero el coste de esta política (PAC) suponía el grueso del gasto del presupuesto de la Unión Europea y se ha ido reduciendo progresivamente. De acuerdo con las negociaciones del GATT, el descenso, además, debe continuar. En la Agenda 2000 (PAC III) el elemento básico de la reforma es la reducción de los precios de garantía de los productos agrarios de la UE para acercarlos a las cotizaciones internacionales. Por lo que se plantea un modelo de agricultura familiar basado no sólo en la competitividad como primer pilar, sino también en el desarrollo rural y la conservación de la naturaleza. Y, para ello, establece ayudas directas o pagos compensatorios para, según la Comisión Europea, tratar de centrar los programas en agricultura ecológica, mantener hábitats y ecosistemas.

España, desde su adhesión, se ha beneficiado, junto a Irlanda, Grecia y Portugal del Fondo de Cohesión, creado en 1993, que aportó una contribución financiera a proyectos relacionados con el medio ambiente y las infraestructuras del transporte, para reducir las divergencias entre las economías de los países miembros. También han llegado ayudas del FEDER para financiar proyectos de desarrollo regional en áreas rurales especialmente deficitarias en infraestructuras o con proyectos viables.

\section{Bibliografía}

ABAD, V. (1991): Cooperativas citrícolas de exportación (1892-1990), Torrent-Valencia, ANECOOP.

ABADÍA, M. (1959): Caja Rural Central y Cooperativa Central del Segura, Orihuela, 1919-1959, XL aniversario de su fundación, Orihuela.

(1994): Caja Rural Central (1919-1994), Orihuela, Caja Rural Central.

ALONSO, M. (1974): «El cooperativismo valenciano: desde sus inicios hasta la ley de 1974», Revista de Debate sobre Economía Pública, Social y Cooperativa nº 11 , Octubre, pp. 53 a 68.

ÁLVAREZ, A. (1968): Història del cooperativisme al País Valencià, Valencia, Lavinia.

APARICIO, D. (1947): Acción Sindical Agraria, Madrid, Sindicatos Agrarios.

BASANTA, C. (2002): Cooperativismo agrario en la Comunidad Valenciana, Tesis inédita; Director: D. Antonio Gil Olcina. Instituto de Geografía. Universidad de Alicante, 2002 , pp. 513.

- (2012): «Proceso de integración de las cooperativas en el aparato administrativo del nacional sindicalismo». En Antoni SEGURA; Andreu MAYAYO (dirs.). La Dictadura franquista: la institucionalizació d'un régim. Barcelona: Edicions i Publicacions de la Universitat de Barcelona, 2012, pp. 498-510.

BEL, P. (1997): Las cooperativas agrarias en España. Análisis de los flujos financieros y de la concentración empresarial, Valencia, CIRIEC-España.

BIGLINO, P. (1986): El socialismo español y la cuestión agraria (1890-1936), Madrid, Ministerio de Trabajo y Seguridad Social.

BONET, J.M.; FERRER, J.M.; ÍNIGUEZ, A. (1989): La acción formativa en las cooperativas agrarias valencianas, Valencia, Conselleria d'Agricultura i Pesca.

BORJABAD I GONZALO, P. (1984): Les societats cooperatives al camp, Lleida, Associació d'Experts Cooperatius, 1986, serie Monografies Cooperatives. Traducció del V.1.

BOTELLA, F. (1972): «Situación actual, problemática y consecuencias de la adhesión de España a la Comunidad Europea», Revista de Estudios Agro-Sociales, n ${ }^{\circ} 78$, eneromarzo, pp. 12-29. 
CABALLER, V.; JULIÁ, J.F.; SEGURA, B. (1987): Las cooperativas agrarias valencianas: un análisis empresarial, Valencia, Conselleria d'Agricultura i Pesca.

CAJA RURAL DE CASTELLÓN (1987): Informe Anual.

CARRIÓN, P. (1973): La Reforma Agraria de la segunda república y la situación actual de la agricultura española, Valencia, Ariel.

- (1974): «La realidad cooperativa agraria en la Región Valenciana», en SANZ JARQUE, J.J.: Curso de Cooperación, Valencia, Universidad Politécnica, pp. 358-392.

CASTAÑO, J. (1996): «El régimen fiscal de las cooperativas y otras consideraciones», Compartir, octubre-diciembre, $\mathrm{n}^{\mathrm{o}} 23$, pp. 42-45.

CIURANA, J.M. y VV.AA. (1963): La empresa artesana y cooperativa a la luz de la doctrina social católica, Madrid, Centro de Estudios Sociales de la Santa Cruz del Valle de los Caídos.

COMISIÓN DE SOCIEDADES COOPERATIVAS DE LA REAL SOCIEDAD DE AMIGOS DEL PAÍS (1868): Lo que son las sociedades cooperativas de consumo. Noticia sobre la organización y ventajas de tales asociaciones seguida de un proyecto de estatutos para el establecimiento en Valencia de una sociedad de esta clase, Valencia, Imprenta de José Rius.

CONSELLERIA d'AGRICULTURA I PESCA (1985): Directorio de Entidades Asociativas Agrarias, Valencia, Generalitat Valenciana.

CORTÉS, J.M., JULIÀ, J.F. (1990): Presente y futuro de la exportación de frutos cítricos en fresco. Análisis de la década de los 80 y perspectivas. Barcelona, AEDOS.

CRUZ, P. (1977): Asociaciones agrarias de comercialización. Empresas asociativas de comercialización de productos agrarios, Madrid, Agrícola Española.

CUESTA, J. (1978): Sindicalismo católico agrario en España (1917-1919), Madrid, Narcea.

DEL ARCO, J.L. (1977): Cooperativismo, una filosofía, una técnica, Zaragoza, Centro Nacional de Educación Cooperativa.

DOBB, M. (1973): Estudios sobre el desarrollo del capitalismo, Buenos Aires, Siglo XXI.

FEDERACIÓN DE CAJAS RURALES (1998): Los avances de una década. Memoria 1988-1998.

FERNÁNDEZ TORRES, J.R. (1998):«La Europa social y la Agricultura», Cuadernos de Agricultura, Pesca y Alimentación, no 3, septiembre-octubre, pp. 5-17.

FONTANA, J. (1975): Cambio económico y actitudes políticas en la España del siglo XIX, Barcelona, Ariel.

GARCÍA NELA, C.F. (1996): Movimiento católico en la ciudad de Castellón. Cooperativa Agrícola y Caja Rural San Isidro. Centenario de la Cooperativa Agrícola San Isidro y Caja Rural Castellón (1896-1996), pp. 138-140.

GARRIDO, S. (1986): Treballar en comú. El cooperativisme agrari a Espanya (1900-1936), Barcelona, Alfons el Magnànim-I.V.I.E.

- (1987): El Sindicalisme catòlic a la Safor, Oliva, C.E.I.C. Alfons el Vell.

- (1996): «Cooperativismo, movilización social, cambio agrario. El gremio de San Isidro», Centenario de la Cooperativa Agrícola San Isidro y Caja Rural Castellón (1896-1996), Castellón, pp. 97-128.

GIL OLCINA, A. (1989): «El impacto del cooperativismo agrario en la organización de las áreas rurales», en V Coloquio de Geografía Agraria, Santiago de Compostela, Universidad de Santiago de Compostela.

GINER SARIOLA, R. (1996): «Los nuevos Principios Cooperativos: ¿al alcance de quién?», Compartir, no 23, pp. 16-18.

GÓMEZ CASAS, J. (1977): Historia del Anarcosindicalismo en España, Madrid, Aguilera. 
GONZÁLEZ PINILLA, J.J. (1986): «Sociedades Agrarias de Transformación», El Campo, enero.

GRUPO CAJA RURAL (1996): Informe Anual.p. 12; 10 años, Madrid, Grupo Caja Rural. GUILLÉN, J.C. (1986): Introducción a la tercera edición de la Ley de Cooperativas de la Comunidad Valenciana y Normas que la desarrollan. Ley 11/1985 de 25 de octubre, Valencia, Conselleria de Treball i Afers Socials.

HERKNER, E. (1916): La cuestión obrera, Madrid, Hijos de Reus, $6^{\mathrm{a}}$ edic., traducida por Faustino Ballvé.

I.C.A.V. (1986): Historia del Cooperativismo Agrario Valenciano, Valencia, I.C.A.V.

- (1986): El Sector Agrario Valenciano, Valencia, Conselleria d'Agricultura i Pesca. Secretaría General, Serveis d'Estudis Agraris i Comunitaris.

I.P.F.C. (1988): Programa de actuación del Instituto de Promoción y Fomento del Cooperativismo durante la vigencia del P.E.V. II (1988-1991), Elche, Conselleria de Treball i Seguretat Social.

- (1992): Ley de Cooperativas de la Comunidad Valenciana y normas que la desarrollan, Elx, Conselleria de Treball i Afers Socials.

ÍÑIGUEZ, A. (1985): «Las sociedades cooperativas para la elaboración y venta de aceite de oliva», El Campo, no 97, pp. 59-62.

JULIÁ, J.F. (1989): «Evolución del cooperativismo agrario en la CEE. Algunas consideraciones en torno al caso español», Revista de Estudios Agrosociales, octubre, $\mathrm{n}^{\circ} 150$, pp. 247-267.

- (1993): «La economía social y el cooperativismo agrario. Sus nuevas estrategias empresariales», Valencia, Revista CIRIEC-España, diciembre, nº 15, pp. 46-68.

JULIÁ, J.F.; SEGURA, B. (1986): El cooperativismo agrario valenciano y su repercusión social presente y futuro, Valencia, I.C.A.V.

JULIÁ, J.F. y SERVER, R.F. (1990): Las organizaciones y agrupaciones de productores agrarios España y la CEE. Aspectos contables y fiscales, Barcelona, Ministerio de Agricultura, Pesca y Alimentación.

KELLNER, H. (1985): «Las cooperativas agrarias en la Comunidad Europea», El Campo, enero-marzo, pp. 74-80.

LASSALA, M. (1909): Nuestra exportación de naranja, Valencia, Imprenta de José Vila Serra.

LLOBREGAT, M.L. (1990): Mutualidad y empresas cooperativas, Barcelona, José M. Bosch.

- (1999) «Régimen económico de las sociedades cooperativas en el marco de la nueva Ley General de Cooperativas de 16 de julio de 1999», RdS, nº 13, pp. 190-229.

LLORENS, M. (1954): «El P. Antoni Vicent S.I. (1837-1912). Notas sobre el desarrollo de la acción social católica en España», en Estudios de Historia Moderna, T. IV, pp. 393-439.

LLUIS I NAVAS, J. (1972): Derecho de Cooperativas, Barcelona, Librería Bosch, T. 1.

MAJUELO, E. y PASCUAL, A. (1991): Del Catolicismo agrario al cooperativismo empresarial. Setenta y cinco años de la Federación de Cooperativas Navarras (1910-1985), Madrid, Ministerio de Agricultura, Pesca y Alimentación.

MARTÍN, A. (1988): La crisis de las Cajas Rurales Españolas y el nuevo modelo del cooperativismo de crédito agrario, Granada, Instituto de Desarrollo Regional de la Universidad de Granada.

MATEO, J. y PALACIO, A. (1972): Cooperativismo, Zaragoza, Centro Nacional de Educación Cooperativa.

MAYAYO, A. (1995): De pagesos a ciutadans. Cent anys de sindicalisme i cooperativisme agraris a Catalunya 1893-1994, Catarroja-Valencia, Afers. 
MINZ, F. (1986): «Revolución y cambio social en la provincia de Alicante», El Anarquismo en Alicante, Alicante, Instituto de Estudios Juan Gil Albert-Diputación de Alicante, pp. 57-67.

MINANA, J. (1986): «La cooperativa de segundo grado Cerezas Montaña de Alicante», Agricultura y Cooperación, marzo, $\mathrm{n}^{\circ} 34$.

MONTERO, A. (1996): El Cooperativismo agroalimentario y formas de integración, Madrid, MAPA.

MOYANO, E. (1984): Corporatismo y Agricultura: Asociaciones profesionales y articulación de intereses en la agricultura española, Madrid, Ministerio de Agricultura, Pesca y Alimentación.

NIVEAU, M. (1979): Historia de los hechos económicos contemporáneos, Barcelona, Ariel.

PASTOR, C. (1999): «Principales novedades de la nueva Ley 27/1999, de 16 de julio, General de Cooperativas», RdS, n 13 , pp. 229-247.

PAVÍA, C. (1992): Historia del Cooperativismo en el País Valenciano (1931-1991). El caso de tres cooperativas históricas de Trabajo Asociado, Valencia, IPFC-Conselleria de Treball i Afers Socials.

PÉREZ I BARÓ, A. (1972): Les cooperatives a Catalunya, Barcelona, Institut d'Estudis Catalans.

PÉREZ PUJOL, E. (1872): La cuestión social en Valencia, Valencia, Imp. José Domenech. PÉREZ TURRANO, M. (1966): Cooperativismo y Política, Madrid, Rial Zyx.

POLO, A. (1867): Memoria sobre las sociedades cooperativas, su organización, sus progresos y su influencia en el porvenir de la clase obrera, Valencia, Soc. Económica de Amigos del País.

RAMOS BASCUÑANA, R. (1880): Algunas ideas sobre la importancia y utilidad de las Cajas de Socorros y Bancos Agrícolas, Alicante, Imp. de Costa y Mira.

REVENTÓS, J. (1960): El movimiento cooperativo en España, Barcelona, Ariel.

RIERA, J.L., CONTELL, J.E. Y VV.AA. (1992): Gestión empresarial. El caso de 18 cooperativas, Alicante, IPFC-Conselleria de Treball i Afers Socials.

RIVAS MORENO, F. (1904): Las Cajas Rurales. El Crédito Agrícola. La Cooperación. El Ahorro, Valencia, Imp. Francisco Vives Mora.

- (1919): Los Bancos Populares, Madrid, Imprenta March y Samarán, Biblioteca de la Cooperación, vol. XII.

- (1926): Los Progresos del campo y la cooperación, Madrid, Librería-casa edit. Hernando.

RODERO, A. (1987): Las Cajas Rurales Españolas. Nacimiento, auge y perspectivas del cooperativismo agrario crediticio en España, Granada, Instituto de Desarrollo Regional de la Universidad de Granada.

- (1972): «Las Cajas Rurales españolas», Revista de Estudios Agro-Sociales, n 78, pp. 8-9.

RODRÍGUEZ, A. (1993): «La Cooperativa, algo más que una Cooperativa», Programa de Fiestas de Callosa de Ensarriá, pp. 124-125.

ROMERO, C. (1981): «De la Ley de Cooperativas de 1942 al reglamento de Sociedades Cooperativas de 1978; un análisis crítico», Rev. Agricultura y Sociedad, V. 18, pp. 33-63.

SÁNCHEZ BLANCO, A. (1982): Región y empresas cooperativas, Salamanca, Escuela Social-Ministerio de Trabajo y Seguridad Social.

SANZ JARQUE, J.J. (1974): Cooperación. Teoría y práctica de las sociedades cooperativas, Valencia, Universidad Politécnica-Departamento de Derecho y Sociología.

TAMAMES, R. (1966): GARCÍA, A. y VV.AA.: España ante la integración económica europea. Barcelona, Ariel. 
TERRÓN, F. (1987): Las Cajas Rurales Españolas. Nacimiento, auge y perspectivas del cooperativismo agrario crediticio en España, Granada, Instituto de Desarrollo Regional de la Universidad de Granada.

TORREGROSA, F.J. (1992): Cultivo y comercialización del níspero en la provincia de Alicante. Modernización por la vía del cooperativismo, Valencia, Conselleria d'Agricultura i Pesca, Generalitat Valenciana.

VALDÉS DAL-RE, F. (1975): Las cooperativas de producción, Madrid, Montecorvo.

VELARDE, J. (1999): «La PAC ha muerto ¡Viva la PAC!», Cuadernos de Agricultura, Pesca y Alimentación, $\mathrm{n}^{\mathrm{o}}$ 8, pp. 3-8.

VICENS, J. (1974): Historia de España y América, social y económica, Barcelona, VicensBolsillo, Vol. V.

VICENT, A. (1893): Socialismo y Anarquismo, Valencia, Imp. José Ortega.

(1905):Cooperativismo católico. Cooperativas de Consumo, de Crédito y de Producción, Valencia, Imp. José Ortega.

VICENTE, L. (1991): Liberalización, Ajuste y Reestructuración de la Agricultura Española, Madrid, Ministerio de Agricultura, Pesca y Alimentación.

WIEIDENFELD, W. y WESSELS, W. (1997): Europa de la A a la Z. Guía de la integración europea, Luxemburgo, Oficina de Publicaciones Oficiales de las Comunidades Europeas.

ZAMARRIEGO B., BURGOS, M.R., MINAYO, G. (1996): Magnitudes macroeconómicas de la Unión Europea I, Madrid, UEM-CEES. 
